\title{
Advances in the Temperature Sensitivity of Soil Respiration and Carbon Balance
}

\author{
Xiang Huang \\ State Key Laboratory of Desert and Oasis Ecology, Xinjiang Institute of Ecology and Geography, CAS, 830011 \\ Urumqi, China \\ email:huangxianghappy@126.com
}

\begin{abstract}
Global warming has led to a positive feedback loop between global carbon cycle and climate system, which will help answer regional climate change and global carbon balance. The sensitivity of soil respiration to temperature change $\left(Q_{10}\right)$ is a very important parameter in the regulation of regional and global carbon balance. Soil respiration increases with the increase of temperature, global warming is believed to stimulate soil respiration, and thus reduce the carbon sequestration intensity of terrestrial ecosystems. However, if soil respiration is not sensitive to long-term changes in temperature, when the temperature rises and the concentration of $\mathrm{CO}_{2}$ increases, the deposition of carbon will be more effective. At present, there are few studies on the role of desert ecosystem in arid area, which is the area of $1 / 4$ of China, and the temperature sensitivity of soil respiration in arid region is generally lower than that of other regions. Comprehensive analysis of domestic and international studies on soil respiration and its temperature sensitivity, and the carbon balance of soil respiration and arid area, is helpful for us to understand the carbon cycle of desert ecosystem and its response to climate change.
\end{abstract}

Keywords-Soil respiration; Desert riparian forest; Ecosystem ; Temperature sensitivity.

\section{INTRODUCTION}

Global warming led to the formation of a positive and negative feedback loop between the global carbon cycle and climate system, all research linked to the carbon cycle that is related to the change of temperature will help answer the regional climate change and global carbon balance. The main soil carbon releasing process from the soil carbon pool (terrestrial ecosystem carbon pool in second) is the soil respiration, as the second large flux in terrestrial ecosystems, small changes in soil respiration can seriously change the atmospheric $\mathrm{CO} 2$ concentration equilibrium, which further affect the global climate stability, therefore, the sensitivity of soil respiration to temperature (Q10) as the control of regional and global carbon balance is one of the key parameters to be concerned. Soil respiration will increase with the increase of temperature, global warming is considered to stimulate soil respiration, thereby reducing the carbon sink strength of terrestrial ecosystems. However, if the soil respiration is not obviously sensitive to long-term changes of temperature, with increasing of the temperature and the concentration of $\mathrm{CO} 2$ in the atmosphere, the carbon sink strength of terrestrial ecosystems will probably be more effective. Huang Xiang found that the soil respiration Q10 value $(0.2 \sim 0.3)$ of Populus euphratica forest in Tarim River is lower than the global average Q10 value (2) nearly to an order of magnitude, and was significantly lower than that of the same latitude forest and grassland (Huang et al., 2007); at the same time, the superposition effect of water also causes the value (Q10) of soil breathing significantly changes (Huang et al., 2011; Huang and Ma, 2012). When the atmospheric $\mathrm{CO} 2$ concentration and the temperature of climate continue to rise, the extremely low Q10 values of Populus euphratica and Tamarix as the main edificators of desert riparian forest in lower reaches of the Tarim River have significant differences on the regional and global (Huang $x$, et al. Ecohydrology), which means the soil respiration in this area will not be irrigated like other ecosystems where nature is excited in the background of global warming,, why causes this difference? Dose this due to the effect of soil substrate, microbial activity, and very low soil moisture content? Or be caused by the results of the joint role of these factors? Whether this can make the ecosystem carbon deposition intensity is increasing, and whether the carbon sink ability will continue to enhance? What are the intrinsic characteristics and mechanisms of soil carbon emissions to climate change? The answers to these questions will help us to understand the carbon cycle process of desert ecosystem and its response to climate change, to provide important scientific basis for the assessment of the value of ecosystem, and provide feasible measures for ecosystem management.

In all biomes, soil respiration rate of desert ecosystem was the lowest; it is often regarded as a small role in global carbon cycle of regulation desert, so the research related to it is the least. However, the area coverage of the earth's land surface is nearly $1 / 4$ of the earth, while the respiratory rate was the lowest, based on the large absolute area, the soil respiration in desert ecosystem impact on regional and global carbon balance is very important. Additional, with the impact and change of climate change and human activities, the area of the desert which is accounting for $41 \%$ of the global land continues to degradating. So the research on the soil respiration in desert ecosystem can not be ignored.

In the past few decades, the studies on the soil respiration are very active, partly because the soil respiration is one of the least understood themes of ecosystem ecology, and also because the soil respiration represents the second flux between atmospheric and terrestrial ecosystems carbon cycle. 
As a key process of ecological system, soil respiration and ecosystem productivity, soil fertility and regional and global carbon cycle are closely related. Because the global carbon cycle controls climate change, soil respiration is also associated with climate change, carbon trading, and environmental policy. In short, the soil respiration has become an interdisciplinary research topic, not only be researched by the ecologist and soil scientist, microbiologist, agronomists and industry attention, atmospheric scientists and biogeochemical scientists, but also concerned by carbon traders and policy makers(Luo and Zhou, 2007)

\section{The Sensitivity of Soll Respiration to TEMPERATURE (Q10)}

In response to the global climate warming, soil respiration may substantially increase the concentration of carbon dioxide in the atmosphere, and is higher than the contribution of human activities, depending on the related mechanism of sensitivity of soil respiration to temperature (Tucker et al., 2013). Soil respiration is very sensitive to environmental changes. The sensitivity of soil respiration to temperature change is a very important parameter to control the global carbon balance. Soil respiration increased with the increase of temperature (and Schlesinger Raich, 1992), as a result of seasonal variation in soil respiration. From this point of view, global warming is believed to stimulate soil respiration, reduce carbon sink strength of terrestrial ecosystems. Cox (Cox et al., 2000) will be a carbon cycle model and a global circulation model and emphasizes the importance of the temperature sensitivity of respiration in climate prediction in the future, this research has stimulated researchers to be interested in the research of the temperature sensitivity of soil respiration.

At present, the positive correlation between soil respiration and temperature has been widely (Eliasson et al. Lloyd and, 2005; Taylor, 1994) and laboratory (Fang et al., 2005a Hartley et; al., 2007) confirmed in field experiment by researchers. This relationship is consistent with the simple physical and chemical laws related to activation energy and enzyme (and Janssens Davidson, 2006). However, it is important that soil heterotrophic respiration in natural systems is not completely controlled by the temperature, but also is influenced by a substrate bioavailability (including intractable number) (Fierer et al. Hartley and, 2005; Ineson, 2008; Kirschbaum, 2004a), and non biological environment (including climate factor), and the intrinsic properties of soil microbial communities (Allison et al. Bradford et, 2010; al., 2008; Lipson et al. Zhou et, 2009; al., 2012). These factors may combine to reduce the sensitivity of soil respiration to temperature. In fact, a growing number of studies have demonstrated that the lowest temperature stimulates the soil respiration (Giardina and Ryan, 2000a) or with the passage of time, temperature stimulation appears to decay (Eliasson et al., 2005; Luo et 2001a; Melillo al., et al., 2002). Due to the similar acclimation of respiration in plants at different ambient temperatures (Atkin and Tjoelker, 2003), this is called "decay heat acclimation" (Kirschbaum, 2004b), "domestication" (Luo et, al., 2001b) or "adaptive" (Bradford et al., 2008). In plants, domestication refers to the physiological process strictly, and refers to an ecosystem level phenomenon, which may push through a variety of mechanisms, including substrate consumption, and changes in microbial community composition (Zhou et al., 2012) and physical changes etc.. Luo (Luo et al., 2001a) did the warming experiment in the natural grassland, which revealed that the "adaptation" phenomenon, due to adapt, after exposure to the experimental ecosystem warming period, soil sensitivity to temperature began to decline, the results of these studies make a challenge generally assumes the global model, which assumed that the decomposition of organic matter respiration carbon release in the process of global warming and the increase of age. However, recent research shows that the temperature sensitivity of soil organic matter decomposition is not changed by the difference of soil depth, the sampling method and the training time (Fang et al., 2005b Knorr et; al., 2005). Using the three base model to analyze soil culture data, and put forward the theory that the temperature sensitivity of turnover slow carbon pool is higher than that of the rapid turnover carbon pool.

The difference of temperature sensitivity of soil respiration has regional and global significance. Global warming will greatly stimulate the role of soil respiration, resulting in more $\mathrm{CO} 2$ released into the atmosphere to capture heat. Therefore, there is a positive feedback loop to be formed between the climate system and the global carbon cycle, and both are strengthened (ET al. Friedlingstein, 2003). The Q10 value based on a fixed global temperature sensitivity (such as 2.0), if the global temperature rise of $2^{\circ} \mathrm{C}$, soil respiration will release additional $10 \mathrm{PgC} \cdot \mathrm{a}^{-1}$ carbon, which is more than the current carbon release amount caused by human activities. The soil organic carbon pool provides a huge storage of carbon, and carbon loss through soil respiration is the main component of the global carbon cycle (Raich and Schlesinger Schlesinger and, 1992; Andrews, 2000). Soil respiration and soil temperature was positively correlated (Lloyd and Taylor, 1994) and the former increase with global warming (Cox et al., 2000), soil heterotrophic respiration on feedback temperature rise is amplified, the emissions of carbon dioxide from soil heterotrophic into the atmosphere is $35 \%$ more than the release caused by human activity(the Cox et al.. 2000). However, the magnitude of this response depends on the sensitivity of soil respiration to temperature (Kirschbaum, 1995, 2004a; et al. Tucker, 2013). Grace and Rayment(Grace and Rayment, 2000) used a relatively simple model to clarify if the respiration increased with long-term temperature increases, the forest carbon sink will be reduced. If respiration is not sensitive to long-term changes of temperature, with the increase of $\mathrm{CO} 2$ in the atmosphere, the carbon deposition will be more effective. Therefore, the hypothesis related to the temperature sensitivity of soil respiration has a profound impact on the long-term prediction of global and regional carbon cycle and climate change.

The temperature sensitivity of soil respiration may also be a key factor to determine the carbon balance in the region. Global warming may lead to a large number of soil carbon loss in hot spots (ET al. Trumbore, 1996). Carbon that is easy to decompose is more stored in the boreal forest and 
tundra where the temperature is expected to rise more greatly The original carbon accumulated in the soil during the cold period, due to response to climate change, with the warming of the soil, it is now being decomposed and released through the soil respiration. Therefore, it is very important to understand the laws of soil respiration in different regions, which is a key factor to predict the regional and global carbon cycle. The coefficient of temperature sensitive of soil respiration and its variation for the accurate understanding of soil respiration is important to study the soil and the "carbon sink" budget and unknown "carbon sink" (Zhao Zhimin and Zhao Chengyi, 2012).

\section{SOIL RESPIRATION AND CARBON BALANCE OF ECOSYSTEM IN ARID AREA}

The change of terrestrial ecosystem carbon fluxes and carbon source / sink evaluation is more and more attention due to the intensification of global climate change. The accurate estimation of GPP, NPP and the change trend of ecosystem respiration and dynamic changes in the future will not only help to understand the carbon cycle and global climate, but also to understand the basis for the fragile ecosystem and evaluation adaptability. Desert ecosystem is one of the most fragile ecosystem, which has the disadvantages of simple structure and weaker resist interference function, and this ecosystem can quickly show the response to environmental change, so the study of dynamic pattern of desert ecosystem carbon storage of desert ecosystem carbon source / sink will help to evaluate and predict the future changes in the ecological environment. Up to now, however, the literature on soil organic carbon is more focused on the huge and fragile carbon storage in humid environment. Although the ecological system of dry land is generally considered to be highly sensitive to environmental changes, its importance in the global carbon cycle has not been paid enough attention (ET al. Schimel, 2003; Asner, 2010). The research on the relationship between soil organic carbon storage and soil depth, eco hydrology, geomorphology process and organic carbon storage is very limited (ET al. Hoffmann, 2012).

The desert and semi-arid ecosystem occupies 35\% of the land surface (Stone et al., 2012), which created the largest biome (Reynolds and Hunter, 2001), and its net primary productivity in the region accounted for about $20 \%$ of the total land productivity (Gao et al., 2012), and stored the $15.5 \%$ of a global organic carbon storage (Lal, 2004). Due to its large area, the characteristics of the rapid response to the micro climate change, arid land ecosystem is usually considered as a hot area of climate change (ET al. Hoffmann, 2012). Under stress, low nutrition level of drought and low vegetation coverage, the carbon of desert and semi-arid regions is considered to be carbon neutral or carbon source for a long time in the terrestrial carbon cycle (Conant et al. Song et, 2000; al., 2012). However, because of human activities, the soil of arid land is more easily to produce degradation and desertification. Most degraded upland soils can be considered to be in highly unsaturated SOC soils, thus the SOC uptake is highly likely (Lal, 2004). And recent results also show that the rate of carbon uptake in the arid region of Israel is similar to that of the European humid forest (and Yakir Rotenberg, 2010). Compared with soil in wet area, the mineralization of SOC is limited by the lack of water in the soil in arid area, which reduces the emission of organic carbon to the atmosphere. Thus, the SOC retention time in the desert soil can be much longer than that in the humid regions of the soil (ET al. Glenn, 1993). Moreover, some recent studies have found that when the carbon flux in the ecosystem level is measured by using the eddy correlation method, arid area appeared carbon absorption phenomenon (Hastings et al. Wohlfahrt et, 2005; al., 2008; Xie et al., 2009), which show that the desert ecosystem is likely to be the "missing sink of atmospheric carbon dioxide" but this is by questioned some desert experts(Schlesinger et al., 2009).

Under the global climate change of the future, the amount of rainfall and time distribution of global or local area will have a certain change. the carbon sink function showed great uncertainty affected by water conditions, sensitive to rainfall change, (Peng Qin et al., 2012). The response of the desert ecosystem to the future atmospheric $\mathrm{CO}_{2}$ concentrations will be significantly affected by the precipitation pattern (either in the 2006). Research has shown that an increase in the temperature and precipitation patterns and climate change under changing will lead to changes in many arid ecosystem structure (such as vegetation composition) and function (such as carbon assimilation changes(Midgley et al., 2004), and change from the carbon source to carbon sequestration (Gao et al., 2012; Mcguire et al., 1995; Raich and Schlesinger, 1992; Rustad and Fernandez, 1998). in addition, due to climatic changes, the scope of arid zone may increase sharply (Maestre and Cortina, 2004) to increase the concentration of carbon dioxide in the atmosphere and climate change, which may lead to an increase of $17 \%$ in the desert area (Emanuel et al., 1985). Considering wide range of these lands increased or decreased in arid and semi arid ecosystem, the global carbon balance and climate change may have been significant influenced (Hastings et al., 2005).

\section{OUTLOOKS}

With the rapid development of desertification, the plant community retrogressive succession occurred. Species composition, plant community coverage and biomass, soil physical and chemical properties changed significantly, which may cause soil respiration and ecosystem carbon sequestration significant changes (Ding Jinzhi et al., 2011). But the current understanding of the process of desert ecosystem succession in soil respiration and carbon balance changes and environmental control mechanism is still not comprehensive, which lead the inaccurate estimates to the wide range of carbon loss in arid areas due to desertification ecosystem (Li Pingheng, 2012). On the other hand, the contribution of carbon sequestration of vegetation restoration in the region is difficult to accurately assess, so it is necessary to conduct in-depth studies (Ding Jinzhi et al., 2011). Therefore, it is recommended that the restoration process of desert riparian forest is choose as the research object, measuring the changes of respiration and soil organic 
carbon and soil respiration in different successional stages and corresponding plant communities, and revealed variation of soil respiration in this area and the environment control mechanism, analysis of the impact of temperature sensitivity of soil respiration and carbon sequestration, and according to the various areas of future climate change of scene simulation scheme, predict the future under climate change scenarios, desert riparian forest soil respiration temperature sensitivity and dynamic change of carbon storage and distribution pattern, provide support for the research of regional carbon balance, and provide a theoretical basis for climate change under the desert riparian forest carbon cycle response mechanism.

It is suggested that the research focuses on the desert riparian forest as the research object, surrounded by the temperature sensitivity of soil respiration index (Q10) lower than the global average of 1 orders of magnitude, start from the ecosystem carbon process as the breakthrough, by separating the quantitative investigation and soil respiration to soil organic carbon groups, and analysis the coupling relationship between the temporal and spatial distribution characteristics of desert riparian forest the soil organic carbon and soil respiration intensity. Meanwhile, it is necessary to attribute all relevant factors affecting soil attribution and reveal the inherent mechanism of desert riparian forest soil respiration according biochemistry, soil aggregates and ecosystem scale why the temperature sensitivity of soil respiration is low in this area, and build the temperature sensitivity of soil respiration model parameters, and determine the intensity of carbon emissions desert riparian forest soil under the effect of low temperature sensitivity; by artificially increasing temperature and humidity control experiment and soil respiration and Joint monitoring of ecosystem respiration, and discuss carbon balance and carbon deposition efficiency in desert riparian forest ecosystem under the background of climate change and its change trend, understand the future change of environment of desert riparian forest ecosystem carbon sink function, and strive to achieve a breakthrough in the loop response mechanism of climate change and its dynamic ecosystem in desert area of carbon.

\section{ACKNOWLEDGMENT}

Work is supported by Natural Science Fund Project of the Xinjiang Uygur Autonomous Region science and Technology Department (2014211A076)

\section{REFERENCES}

[1] Allison SD, Wallenstein MD, Bradford MA (2010) Soil-carbon response to warming dependent on microbial physiology. Nature Geoscience 3: 336-340

[2] Asner GP, Borghi CE, Ojeda RA (2003) Desertification in Central Argentina: changes in ecosystem carbon and nitrogen from imaging spectroscopy. Ecol Appl 13: 629-648

[3] Atkin OK, Tjoelker MG (2003) Thermal acclimation and the dynamic response of plant respiration to temperature. Trends Plant Sci 8: 343351 Bradford MA, Davies CA, Frey SD, Maddox TR, Melillo JM, Mohan JE,
[4] Reynolds JF, Treseder KK, Wallenstein MD (2008) Thermal adaptation of soil microbial respiration to elevated temperature. Ecol Lett 11: 1316-1327

[5] Conant RT, Klopatek JM, Klopatek CC (2000) Environmental factors controlling soil respiration in three semiarid ecosystems. Soil Sci Soc Am J 64: 383-390

[6] Cox PM, Betts RA, Jones CD, Spall SA, Totterdell IJ (2000) Acceleration of global warming due to carbon-cycle feedbacks in a coupled climate model. Nature 408: 184-187

[7] Davidson EA, Janssens IA (2006) Temperature sensitivity of soil carbon decomposition and feedbacks to climate change. Nature 440: 165-173

[8] Eliasson PE, McMurtrie RE, Pepper DA, Stromgren M, Linder S, Agren GI (2005) The response of heterotrophic CO2 flux to soil warming. Global Change Biol 11: 167-181

[9] Emanuel WR, Shugart HH, Stevenson M (1985) Climatic-Change And the Broad-Scale Distribution Of Terrestrial Ecosystem Complexes - Response. Climatic Change 7: 457-460

[10] Fang CM, Smith P, Moncrieff JB, Smith JU (2005a) Similar response of labile and resistant soil organic matter pools to changes in temperature. Nature 433: 57-59

[11] Fierer N, Craine JM, McLauchlan K, Schimel JP (2005) Litter quality and the temperature sensitivity of decomposition. Ecology 86: 320326

[12] Friedlingstein P, Dufresne JL, Cox PM, Rayner P (2003) How positive is the feedback between climate change and the carbon cycle? Tellus B 55: 692-700

[13] Gao YH, Li XR, Liu LC, Jia RL, Yang HT, Li G, Wei YP (2012) Seasonal variation of carbon exchange from a revegetation area in a Chinese desert. Agr Forest Meteorol 156: 134-142

[14] Giardina CP, Ryan MG (2000) Evidence that decomposition rates of organic carbon in mineral soil do not vary with temperature. Nature 404: 858-861

[15] Glenn S, Heyes A, Moore T (1993) Carbon-Dioxide And Methane Fluxes From Drained Peat Soils, Southern Quebec. Global Biogeochem Cy 7: 247-257

[16] Grace J, Rayment M (2000) Respiration in the balance. Nature 404: 819-820

[17] Hartley IP, Heinemeyer A, Evans SP, Ineson P (2007) The effect of soil warming on bulk soil vs. rhizosphere respiration. Global Change Biol 13: 2654-2667

[18] Hartley IP, Ineson P (2008) Substrate quality and the temperature sensitivity of soil organic matter decomposition. Soil Biol Biochem 40: $1567-1574$

[19] Hastings SJ, Oechel WC, Muhlia-Melo A (2005) Diurnal, seasonal and annual variation in the net ecosystem $\mathrm{CO} 2$ exchange of a desert shrub community (Sarcocaulescent) in Baja California, Mexico. Global Change Biol 11: 927-939

[20] Hoffmann U, Yair A, Hikel H, Kuhn NJ (2012) Soil organic carbon in the rocky desert of northern Negev (Israel). Journal Of Soils And Sediments 12: 811-825

[21] Huang X, Chen YN, Li WH, Ma JX, Chen YP (2007) Daily variation of carbon flux in soils of Populus euphratica forests in the middle and lower reaches of the Tarim River. Prog Nat Sci 17: 584-590

[22] Huang X, Chen YN, Ma JX, Li WH (2011) Special Variation of Soil Respiration and Its Effecting Factors in Temperate Deserts, China. 2011 3rd International Conference on Environmental Science And Information Application Technology Esiat 2011, Vol 10, Pt A 10: 228-238

[23] Huang X, Ma JX (2012) the influence of groundwater on soil respiration rate of Populus euphratica community at lower reaches of Tarim River, Xinjiang, China. Journal Of Food Agriculture \& Environment 10: 1468-1472

[24] IPCC (2007) Chapter 7: Couplings between changes in the climate system and biogeochemistry. In: Climate Change 2007: Thephysical science basis. Contribution of Working Group I to the Fourth 
Assessment Report of the Intergovernmental Panel on Climate Change. Cambridge University Press, Cambridge

[25] Kirschbaum MUF (1995) The Temperature-Dependence Of Soil Organic-Matter Decomposition, And the Effect Of Global Warming on Soil Organic-C Storage. Soil Biol Biochem 27: 753-760

[26] Kirschbaum MUF (2004a) Soil respiration under prolonged soil warming: are rate reductions caused by acclimation or substrate loss? Global Change Biol 10: 1870-1877

[27] Knorr W, Prentice IC, House JI, Holland EA (2005) Long-term sensitivity of soil carbon turnover to warming. Nature 433: 298-301

[28] Lal R (2004) Carbon sequestration in dryland ecosystems. Environ Manage 33: 528-544

[29] Lipson DA, Monson RK, Schmidt SK, Weintraub MN (2009) The trade-off between growth rate and yield in microbial communities and the consequences for under-snow soil respiration in a high elevation coniferous forest. Biogeochemistry 95: 23-35

[30] Lloyd J, Taylor JA (1994) On the Temperature-Dependence Of Soil Respiration. Funct Ecol 8: 315-323

[31] Luo Y, Zhou X (2007) Soil respiration and environment. In: Jianglifen, Qulaiye, Zhouyumei,Wenyixin. Long River scholars forum. Higher education press. Beijing

[32] Luo YQ, Wan SQ, Hui DF, Wallace LL (2001a) Acclimatization of soil respiration to warming in a tall grass prairie. Nature 413: 622-625

[33] Maestre FT, Cortina J (2004) Do positive interactions increase with abiotic stress? - A test from a semi-arid steppe. Proceedings Of the Royal Society B-Biological Sciences 271: S331-S333

[34] Mcguire AD, Melillo JM, Joyce LA (1995) The Role Of Nitrogen In the Response Of Forest Net Primary Production To Elevated Atmospheric Carbon-Dioxide. Annual Review Of Ecology And Systematics 26: 473-503

[35] Melillo JM, Steudler PA, Aber JD, Newkirk K, Lux H, Bowles FP, Catricala C, Magill A, Ahrens T, Morrisseau S (2002) Soil warming and carbon-cycle feedbacks to the climate system. Science 298: 21732176

[36] Midgley GF, Aranibar JN, Mantlana KB, Macko S (2004) Photosynthetic and gas exchange characteristics of dominant woody plants on a moisture gradient in an African savanna. Global Change Biol 10: 309-317

[37] Raich JW, Schlesinger WH (1992) The Global Carbon-Dioxide Flux In Soil Respiration And Its Relationship To Vegetation And Climate. Tellus B 44: 81-99

[38] Reynolds BC, Hunter MD (2001) Responses of soil respiration, soil nutrients, and litter decomposition to inputs from canopy herbivores. Soil Biol Biochem 33: 1641-1652

[39] Rotenberg E, Yakir D (2010) Contribution of semi-arid forests to the climate system. Science 327: 327-451

[40] Rustad LE, Fernandez IJ (1998) Experimental soil warming effects on $\mathrm{CO} 2$ and $\mathrm{CH} 4$ flux from a low elevation spruce-fir forest soil in Maine, USA. Global Change Biol 4: 597-605

[41] Schimel DS (2010) Drylands in the Earth System. Science 327: 418419

[42] Schlesinger WH, Andrews JA (2000) Soil respiration and the global carbon cycle. Biogeochemistry 48: 7-20
[43] Schlesinger WH, Belnap J, Marion G (2009) On carbon sequestration in desert ecosystems. Global Change Biol 15: 1488-1490

[44] Song WM, Chen SP, Wu B, Zhu YJ, Zhou YD, Li YH, Cao YL, Lu Q, Lin GH (2012) Vegetation cover and rain timing co-regulate the responses of soil CO2 efflux to rain increase in an arid desert ecosystem. Soil Biol Biochem 49: 114-123

[45] Stone MM, Weiss MS, Goodale CL, Adams MB, Fernandez IJ, German DP, Allison SD (2012) Temperature sensitivity of soil enzyme kinetics under $\mathrm{N}$-fertilization in two temperate forests. Global Change Biol 18: 1173-1184

[46] Tucker CL, Bell J, Pendall E, Ogle K (2013) Does declining carbonuse efficiency explain thermal acclimation of soil respiration with warming? Global Change Biol 19: 252-263

[47] Wohlfahrt G, Hammerle A, Haslwanter A, Bahn M, Tappeiner U, Cernusca A (2008) Seasonal and inter-annual variability of the net ecosystem CO2 exchange of a temperate mountain grassland: Effects of weather and management. J Geophys Res 113

[48] Xie JX, Li Y, Zhai CX, Li CH, Lan ZD (2009) CO2 absorption by alkaline soils and its implication to the global carbon cycle. Environ Geol 56: 953-961

[49] Zhou JZ, Xue K, Xie JP, Deng Y, Wu LY, Cheng XH, Fei SF, Deng SP, He ZL, Van Nostrand JD, Luo YQ (2012) Microbial mediation of carbon-cycle feedbacks to climate warming. Nature Climate Change 2: $106-110$

[50] Zhou XQ, Wu HW, Koetz E, Xu ZH, Chen CR (2012) Soil labile carbon and nitrogen pools and microbial metabolic diversity under winter crops in an arid environment. Appl Soil Ecol 53: 49-55

[51] Ding Jinzhi, Lai liming, Zhao Xuechun, Zhu Linhai, Jiang liming, Zheng Yuanrun, (2011). Effects of desertification on soil respiration and ecosystem carbon sequestration in Maowusu Sandy Land. Journal of Ecology: 1594-1603

[52] Fang Fei, Hu Yukun, Yang Xiujuan, Gong Ming, Liu Yanyan (2012) the distribution characteristics of organic carbon and microbial biomass under different desert ecosystems. The resources and environment of arid area: 59-63

[53] Li Pingheng, Zhou Qi, King (2012) Simulation of net primary productivity of typical desert ecosystem in arid area and its response to climate change. To strengthen the basic science and technology promote the modernization of meteorological -- twenty-ninth China Meteorological Society annual meeting, China Liaoning Shenyang, P 431

[54] Peng Qin, Qi Yuchun, Dong Yun, He Yating, Liu Xinchao, Sun Liangjie, Jia Junqiang, Jin (2012), the response of the key process of grassland carbon cycle to the change of rainfall in arid and semi-arid regions. Progress in geographical science: 1510-1518

[55] Ren Hui Li, Li Ping, Shen Weijun, Ren Hai, Yang Fan (2006) the difference of response of desert ecosystem to increase atmospheric $\mathrm{CO} 2$ concentration between wet and dry years. Journal of tropical and subtropical plants: 389-396

[56] Zhao Harlem Yu, Li Yuqiang, Zhou Ruilian (2009) the influence of sandy desertification in Horqin on soil respiration and carbon balance of sandy grassland. The effects of Soil Science: 809-816

[57] Zhao Zhimin, Zhao Chengyi (2012) research on the temperature sensitivity of soil respiration of the Tarim River Basin in arid areas of. Glacier: 169-176 